\title{
Exogenous female sex steroid hormones and risk of asthma and asthma-like symptoms: a cross sectional study of the general population
}

\author{
P Lange, J Parner, E Prescott, C Suppli Ulrik, J Vestbo
}

\begin{abstract}
Background-Recent evidence suggests a role for hormonal factors in the aetiology of asthma.

Methods-Data from a large study of women selected from the general population were used to relate treatment with oral hormonal contraceptives (OCP) and postmenopausal hormone replacement therapy (HRT) to the following asthma indicators: self-reported asthma, wheezing, cough at exertion, and use of medication for asthma. The study sample comprised 1536 premenopausal and 3016 postmenopausal women who participated in the third round of the Copenhagen City Heart Study in 1991-4. A total of 377 women were taking OCP $(24.5 \%$ of premenopausal women) and 458 were on HRT (15.2\% of postmenopausal women).

Results-In premenopausal women $4.8 \%$ reported having asthma. The prevalence of self-reported asthma, wheeze, use of asthma medication, and cough at exertion was not significantly related to use of OCP. In postmenopausal women the prevalence of self-reported asthma was $6.2 \%$. A weak but consistent association was observed between HRT and self-reported asthma (OR 1.42 (95\% CI 0.95 to 2.12)), wheeze (OR 1.29 (95\% CI 1.02 to 1.64$)$ ), cough at exertion (OR 1.34 (95\% CI 1.01 to 1.77$)$ ), and use of asthma medication (OR 1.45 (95\% CI 0.97 to 2.18)).
\end{abstract}

Conclusions-In this study of the general population no relationship was found between the use of OCP and asthma. Although an association was observed between HRT and asthma and asthmalike symptoms, this was relatively weak and it is concluded that there is no necessity to change present prescription practice.

(Thorax 2001;56:613-616)

Keywords: asthma; hormone replacement therapy; oral contraceptives; female sex steroid hormones

Medicine

Kommunehospitalet,

Denmark

E Prescott

Correspondence to: Dr P Lange

peter.lange@hh.hosp.dk

Received 23 October 2000 Returned to authors

14 February 2001

Revised version received

9 April 2001

Accepted for publication

8 May 2001 during the menstrual cycle, and disease severity is also affected by pregnancy. Furthermore, since up to $30 \%$ of women take exogenous oestrogens alone or together with progesterone, hormonal factors have been suggested as modifiers of asthma severity. ${ }^{6}$ As treatment with sex hormones may increase disease severity in some asthmatic women, it may also be reflected by an increased prevalence of asthma symptoms and use of asthma medication in women on this treatment. In keeping with this, Troisi and co-workers reported a significant association between treatment with sex hormones and adult onset asthma in an epidemiological study of more than 100000 nurses in the USA. ${ }^{7}$ Yet, in a recent survey of 461 women with asthma recruited from general practice, Forbes et al did not observe an increase in asthma severity in women on oral hormonal contraceptives (OCP). ${ }^{8}$

The purpose of the present investigation was to analyse the prevalence of asthma in relation to treatment with exogenous sex hormones in women randomly selected from the general population. We used data from the third examination round of the Copenhagen City Heart Study comprising 4552 women living in the city of Copenhagen and related treatment with OCP and postmenopausal hormonal replacement therapy (HRT) to self-reported asthma, asthma symptoms, and use of medication for asthma.

\section{Methods}

All the women included in the present analyses participated in the third round of the Copenhagen City Heart Study, a prospective epidemiological cardiopulmonary study initially started in $1976 .{ }^{9}$ The original population sample was drawn in January 1976 from the Copenhagen population register of a population of approximately 90000 inhabitants aged 20 years or more. The sample was age stratified with the main emphasis being placed on those aged 35-70 years. The cohort was investigated for the first time in 1976-8, for the second time in 1981-3, and for the third time in 1991-4. At the third examination the cohort consisted of the subjects that had been included in previous investigations and an additional sample of 3000 subjects aged 20-39 years. A total of 5685 women and 4450 men participated in this examination (response rate $61.2 \%$ ). In general, the response rates were highest among subjects aged $40-70$ years $(68-80 \%)$ and lowest among those aged 80 years or more (28-41\%). Previous investigations of non-responders performed at the first examination showed that the 
Table 1 General characteristics of premenopasual and postmenopausal women according to use of oral contraceptive pill (OCP) and hormonal replacement therapy (HRT)

\begin{tabular}{lllll}
\hline Characteristic & $\begin{array}{l}\text { Premenopausal } \\
- \text { OCP }(n=1159)\end{array}$ & $\begin{array}{l}\text { Premenopausal } \\
+ \text { OCP }(n=377)\end{array}$ & $\begin{array}{l}\text { Postmenopausal } \\
- \text { HRT }(n=2558)\end{array}$ & $\begin{array}{l}\text { Postmenopausal } \\
+ \text { HRT }(n=458)\end{array}$ \\
\hline Age (years) & $40.0(9.4)$ & $38.5(10.6)$ & $67.1(8.9)$ & $62.0(8.1)$ \\
Length of school education (years) & $10.9(1.9)$ & $10.8(2.0)$ & $8.4(1.8)$ & $8.8(1.9)$ \\
Smoking (\%): & 32.4 & 31.3 & 31.7 & 30.6 \\
$\quad$ Never smokers & 20.1 & 21.2 & 43.8 & 21.6 \\
$\quad$ Ex-smokers & 47.5 & 47.5 & 24.5 & 47.8 \\
$\quad$ Current smokers & $23.6(3.9)$ & $23.6(3.9)$ & $26.1(4.9)$ & $24.7(3.8)$ \\
BMI (kg/m $\left.{ }^{2}\right)$ & 21.1 & 19.4 & 22.9 & 21.0 \\
Familial disposition to asthma (\%) & & & & \\
\hline
\end{tabular}

Values are mean $(\mathrm{SD})$.

prevalence of asthma in the non-responders investigated in their homes was slightly higher than in the responders. ${ }^{10}$

After excluding 440 women with incomplete data required for the present analyses, the final study sample comprised 1536 premenopausal and 3016 postmenopausal women. Information on hormonal treatment was obtained from the questionnaire. The women were classified as premenopausal or postmenopausal on the basis of the questionnaire according to whether they were still menstruating or had entered the menopause; they also reported whether or not they were taking OCP or HRT. No details were obtained concerning the type of sex hormones being taken.

Based on the information from the questionnaire, the following asthma indicators were investigated:

- Self-reported asthma (an affirmative answer to the question "Do you have asthma?")

- Wheezing

- Use of asthma medication

- Cough at exertion

In addition to cross tabulation of these asthma indicators in relation to the use of exogenous hormones, several multiple logistic regression analyses were performed with each of the asthma indicators as the dependent variable, use of hormones as the independent variable of interest, and age, length of school education, body mass index (BMI), smoking, and familiar predisposition to asthma as covariates. Separate analyses were performed on use of OCP in premenopausal women and on HRT in postmenopausal women. All reported $\mathrm{p}$ values are based on two sided tests of significance and a $p$ value of $<0.05$ was considered significant. The possible interactions between different variables were assessed using the log likelihood test.

\section{Results}

A total of 377 women were on OCP $(24.5 \%$ of premenopausal women) and 458 were on HRT (15.2\% of postmenopausal women). The age span of premenopausal women was 21-49 years and of postmenopausal women was

Table 2 Distribution of asthma and asthma-like symptoms according to treatment with hormonal contraceptives in 1536 premenopausal women

\begin{tabular}{llll}
\hline & $\begin{array}{l}\text { No hormonal } \\
\text { contraception }(n=1159)\end{array}$ & $\begin{array}{l}\text { Hormonal } \\
\text { contraception }(n=377)\end{array}$ & p value \\
\hline Asthma $(\mathrm{n}=74)$ & $56(4.8 \%)$ & $18(4.8 \%)$ & 0.964 \\
Wheezing $(\mathrm{n}=63)$ & $295(25.5 \%)$ & $96(25.5 \%)$ & 0.997 \\
Asthma medication $(\mathrm{n}=63)$ & $45(3.9 \%)$ & $18(4.8 \%)$ & 0.448 \\
Coughing at exertion $(\mathrm{n}=220)$ & $167(14.4 \%)$ & $53(14.1 \%)$ & 0.866 \\
\hline
\end{tabular}

27-90 years. The general characteristics of women taking and not taking exogenous sex hormones are shown in table 1 . In both premenopausal and postmenopausal women those taking sex hormones were younger; the remaining characteristics differed very little.

The prevalence of the chosen asthma indicators in premenopausal women according to treatment with OCP is shown in table 2 . None of the asthma indicators was more prevalent in the subgroup on hormonal contraception. Stratification of the women according to smoking habits did not change the results. Similarly, no significant association between any asthma indicator and OCP was seen when using multiple logistic regression with age, length of school education, BMI, and smoking as covariates (not shown).

In postmenopausal women preliminary analyses suggested differences in smoking subgroups and therefore the results are presented separately for never smokers, ex-smokers, and smokers (table 3). In most of the comparisons the asthma indicators were not significantly more prevalent in the women on HRT. However, in never smokers there was a higher prevalence of self-reported asthma and asthma medication in those on HRT (table 3).

The results of multiple logistic regression of the effects of HRT and smoking on asthma indicators in postmenopausal women together with various covariates are shown in table 4 . The odds ratios (ORs) for all four asthma indicators were higher in women on HRT with $p$ values of approximately 0.05 and confidence intervals close to 1 (table 4). As expected, the ORs were higher in women with familial predisposition to asthma and short school education. A high BMI was significantly related to wheezing but not to the remaining asthma indicators. Smoking was strongly related to all asthma indicators.

Because of the trends observed in table 3, additional analyses were performed to explore the possible interaction between HRT and smoking on asthma indicators. A borderline interaction $(p=0.03)$ was found which showed that HRT was associated with a much higher risk of asthma in never smokers (OR 3.3 (95\% CI 1.6 to 7.1 )) than in current smokers (OR $1.2(95 \%$ CI 0.7 to 2.1$)$. A similar interaction $(p=0.05)$ was observed for asthma medication but not for wheezing and cough at exertion.

\section{Discussion}

In this study of women selected from the general population, we could not demonstrate any 
Table 3 Distribution of asthma and asthma-like symptoms according to hormonal replacement therapy (HRT) and smoking among 3016 postmenopausal women

\begin{tabular}{|c|c|c|c|c|c|c|c|c|c|}
\hline & \multicolumn{3}{|l|}{ Never smokers } & \multicolumn{3}{|l|}{ Ex-smokers } & \multicolumn{3}{|c|}{ Current smokers } \\
\hline & $\begin{array}{l}-H R T \\
(n=812)\end{array}$ & $\begin{array}{l}+H R T \\
(n=140)\end{array}$ & p value & $\begin{array}{l}-H R T \\
(n=626)\end{array}$ & $\begin{array}{l}+H R T \\
(n=99)\end{array}$ & $p$ value & $\begin{array}{l}-H R T \\
(n=1120)\end{array}$ & $\begin{array}{l}+H R T \\
(n=219)\end{array}$ & $p$ value \\
\hline Asthma & $24(3 \%)$ & $11(7.9 \%)$ & 0.004 & $48(7.7 \%)$ & $7(7.1 \%)$ & 0.84 & $81(7.2 \%)$ & $17(7.8 \%)$ & 0.78 \\
\hline Wheeze & $109(13.4 \%)$ & $17(12.1 \%)$ & 0.680 & $124(19.8 \%)$ & $26(26.3 \%)$ & 0.14 & $414(37 \%)$ & $88(40 \%)$ & 0.40 \\
\hline Asthma medication & $25(3.1 \%)$ & $10(7.14 \%)$ & 0.018 & $43(6.9 \%)$ & $5(5.1 \%)$ & 0.66 & $80(7.1 \%)$ & $19(8.7 \%)$ & 0.40 \\
\hline Cough at exertion & $68(8.4 \%)$ & $14(10 \%)$ & 0.527 & $77(12.3 \%)$ & $14(14.1 \%)$ & 0.62 & $209(18.7 \%)$ & $51(23.3 \%)$ & 0.11 \\
\hline
\end{tabular}

significant association between OCP and asthma, use of asthma medication, and asthma related symptoms. A relatively weak association was detected with HRT, suggesting that postmenopausal women on HRT have a slightly higher risk of asthma and asthma-like symptoms. The size of the population makes it unlikely that important negative effects of exogenous female sex hormones on asthma were undetected.

With regard to OCP, our results are clear and reassuring. Oral contraceptive pills reduce the dynamic fluctuations in oestrogen and progesterone levels over the menstrual cycle and, given that these cyclic changes cause changes in asthma severity, OCP might reduce their amplitude and thus make asthma more stable. This assumption is in line with most previous reports which have shown that OCP may reduce airway responsiveness, peak flow variability, and perceived severity of asthma. ${ }^{11}{ }^{12}$ These findings are, however, not uniform and observations from a few small studies have even suggested that administration of exogenous sex hormones to premenopausal women may make asthma worse. ${ }^{13-15}$ However, a recent general practice based study of asthmatic women by Forbes et al found no significant differences in asthma quality of life scores between women on OCP and those not taking exogenous hormones. ${ }^{8}$ Furthermore, only $4 \%$ of the participants reported worsening of their asthma due to the hormonal contraceptives, and these women had significantly worse asthma than the remaining group of participants. This study therefore suggests that, at least in women with relatively mild asthma, oral hormonal contraceptives do not have a pronounced influence on symptom severity. Although our approach differs by looking at a sample of the general population, a lack of association between OCP and asthma and asthma-like symptoms is in keeping with the findings of Forbes et al. ${ }^{8}$

Postmenopausal women have very limited fluctuations in endogenous sex hormones which, at least theoretically, makes it less likely that HRT would have a substantial impact on asthma symptoms. ${ }^{6}$ However, oestrogen enhances the production of corticosteroid binding globulin and progesterone competes with cortisol for binding sites. Thus, both oestrogen and progesterone may influence the level of free cortisol, leading to decreased levels. Furthermore, it has previously been hypothesised that oestrogen may induce resistance to cortisol in both peripheral tissues and the central nervous system. However, in line with these contradictory theoretical considerations, both smaller clinical studies and case studies of the influence of HRT on asthma severity have reported conflicting observations, some showing remarkable improvement in symptoms and others a pronounced worsening. ${ }^{16-19}$ Sex steroid hormones may play a role in the expression of asthma in susceptible individuals, but the only available epidemiological evidence for an association between HRT and adult onset asthma comes from the Nurses' Health Study ${ }^{7}$ which showed not only that oestrogen is likely to play a role in the pathophysiology of asthma, but also that long term use and/or high doses of postmenopausal HRT significantly increased the risk for subsequent development of asthma. Although our cross sectional findings of a weak association between HRT and asthma indicators support the hypothesis of a deleterious effect of exogenous female sex hormones on asthma, the association was weak. After stratification for smoking habits, the strongest association was seen between asthma/asthma medication and

Table 4 Hormone replacement therapy (HRT) and risk of asthma and asthma-like symptoms in postmenopausal women

\begin{tabular}{|c|c|c|c|c|}
\hline Predictors & $\begin{array}{l}\text { Asthma } \\
(n=188)\end{array}$ & $\begin{array}{l}\text { Wheezing } \\
(n=718)\end{array}$ & $\begin{array}{l}\text { Cough at exertion } \\
(n=433)\end{array}$ & $\begin{array}{l}\text { Asthma medication } \\
(n=182)\end{array}$ \\
\hline Age (per 1 year) & $1.01(0.99$ to 1.03$)$ & $0.99(0.98$ to 1.01$)$ & $0.99(0.99$ to 1.01$)$ & $1.02(0.99$ to 1.04$)$ \\
\hline \multicolumn{5}{|l|}{$\mathrm{BMI}\left(\mathrm{kg} / \mathrm{m}^{2}\right)$} \\
\hline$<20$ & 1.0 & 1.0 & 1.0 & 1.0 \\
\hline $20-25$ & $1.02(0.72$ to 1.42$)$ & $1.59(1.31$ to 1.93$)$ & $1.17(0.93$ to 1.47$)$ & 0.94 (0.67 to 1.32$)$ \\
\hline$>25$ & $0.95(0.61$ to 1.47$)$ & $2.13(1.67$ to 2.71$)$ & $1.12(0.83$ to 1.51$)$ & $0.87(0.55$ to 1.36$)$ \\
\hline $\begin{array}{l}\text { Familial disposition to } \\
\text { asthma (yes) }\end{array}$ & $3.16(2.32$ to 4.29$)$ & $1.51(1.24$ to 1.84$)$ & $1.21(0.96$ to 1.54$)$ & $2.10(1.53$ to 2.89$)$ \\
\hline \multicolumn{5}{|l|}{ Education (years) } \\
\hline$>10$ & 1.0 & 1.0 & 1.0 & 1.0 \\
\hline $7-10$ & $1.22(0.82$ to 1.80$)$ & $1.58(1.27$ to 1.97$)$ & 1.59 (1.22 to 2.06$)$ & $1.53(1.03$ to 2.28$)$ \\
\hline$<7$ & $1.26(0.82$ to 1.94$)$ & $1.34(1.04$ to 1.71$)$ & $1.17(0.86$ to 1.60$)$ & $1.37(0.87$ to 2.16$)$ \\
\hline \multicolumn{5}{|l|}{ Smoking: } \\
\hline Never smoker & 1.0 & 1.0 & 1.0 & 1.0 \\
\hline Ex-smoker & $2.16(1.39$ to 3.36$)$ & $1.79(1.37$ to 2.32$)$ & $1.56(1.14$ to 2.14$)$ & 1.89 (1.21 to 2.97$)$ \\
\hline Current smoker & $1.99(1.32$ to 3.00$)$ & $4.26(3.39$ to 5.35$)$ & $2.51(1.91$ to 3.29$)$ & $2.06(1.37$ to 3.09$)$ \\
\hline \multicolumn{5}{|l|}{ HRT } \\
\hline No & 1.0 & 1.0 & 1.0 & 1.0 \\
\hline Yes & $1.42(0.95$ to 2.12$)$ & $1.29(1.02$ to 1.64$)$ & $1.34(1.01$ to 1.77$)$ & 1.45 (0.97 to 2.18$)$ \\
\hline
\end{tabular}

Odds ratios derived from multiple logistic regression with $95 \% \mathrm{CI}$ in parentheses. 
HRT in never smokers. However, we did not observe a clear increase in asthma symptoms (wheeze and cough) in this smoking subgroup (table 3). The most likely explanation for this discrepancy is that postmenopausal women on HRT are more likely to visit their GPs than women not on HRT and, if they are never smokers, they more likely to have their respiratory symptoms diagnosed as asthma and to receive asthma medication. Another possible explanation is that, because of the strong influence of smoking on asthma-like symptoms, a potential association between HRT and asthma is only detectable in non-smokers. A third possible explanation for the interaction between HRT and smoking in asthma is that the deleterious effect of HRT is counteracted by the antioestrogenic effect of smoking. Although these explanations are speculative at present, previous studies have suggested that smoking may exert an anti-oestrogenic effect by altering the metabolism of endogenous and exogenous sex hormones. ${ }^{20} 21$ Finally, although self-reported asthma has been shown to be a valid indicator of asthma in epidemiological settings, ${ }^{22}$ some degree of misclassification in postmenopausal women has probably occurred in our study with some subjects with mild asthma remaining undiagnosed and others with chronic obstructive pulmonary disease being diagnosed as asthmatics.

We conclude that there is no relationship between the use of oral hormonal contraceptives and asthma and asthma-like symptoms in the general population, while HRT after the menopause seems to be associated with a slightly higher risk of asthma. However, since this association was relatively weak, we think that further studies are needed and that present prescription policies in postmenopausal women do not yet need to be changed.

This study was supported by grants from The Danish Lung Association, The Danish Heart Foundation and The Danish Medical Research Council.
1 Woolcock AJ. The problem of asthma world-wide. Eur Respir Rev 1991;1:243-6.

2 Manfreda J, Becker AB, Wang PZ, et al. Transient physician diagnosed asthma. Prevalence in Manitoba between 1980 and 1990. Chest 1993;103:158-67.

3 Yunginger JW, Reed CE, O'Connell EJ, et al. A community based study of the epidemiology of asthma: incidence rates, 1964-1983. Am Rev Respir Dis 1992;146:888-94.

4 Skobeloff EM, Spivey WH, St Clair SS, et al. The influence of age and sex on asthma admissions. $F A M A$ 1992;268: 3437-40.

5 Prescott E, Lange P, Vestbo J. Effect of gender on hospital admissions for asthma and prevalence of self-reported asthma: a prospective study based on a sample of the genasthma: a prospective study based on a

6 Forbes L. Do exogenous oestrogens and progesterone influence asthma? Thorax 1999;54:265-7.

7 Troisi RJ, Speizer FE, Willet WC, et al. Menopause, postmenopausal oestrogen preparations, and the risk of adult-onset asthma. Am F Respir Crit Care Med 1995;152: $1183-8$.

8 Forbes L, Jarvis D, Burney P. Do hormonal contraceptives influence asthma severity. Eur Respir f 1999;14:1028-33.

9 Appleyard M, ed. The Copenhagen City Heart Study. Scand f Soc Med 1989;Suppl 41.

10 Jensen G. Epidemiology of chest pain and angina pectoris. Acta Med Scand Suppl 1984; 682 .

11 Tan KS, McFarlane LC, Lipworth BJ. Loss of normal cyclical $\beta 2$-adrenoceptor regulation and increased premenstrual responsiveness to adenosine monophosphate in stable female asthmatic patients. Thorax 1997;52:608-11.

12 Chandler MHH, Schuldheisz S, Philips BA, et al. Premenstrual asthma: the effect of oestrogen on symptoms, pulmonary function, and $\beta_{2}$-receptors. Pharmacotherapy 1997;17:224-34.

13 Ensom MH, Chong E, Carter D. Pre-menstrual symptoms in women with pre-menstrual asthma. Pharmacotherapy 1999;19:374-82.

14 Horan JD, Lederman JJ. Possible asthmogenic effect of oral contraceptives. Can Med Assoc 7 1968;99:130-1.

15 Tan KS, McFarlane LC, Lipworth BJ. Paradoxical downregulation and desensitisation of $\beta_{2}$ adrenoceptors by exogenous progesterone in female asthmatics. Chest 1997;111: $847-51$

16 Liebermann D, Kopernik G, Porath A. Influence of oestrogen replacement therapy on airway reactivity. Respiration 1995;21:153-7.

17 Liebermann D, Kopernik G, Porath A. Subclinical worsening of bronchial asthma during oestrogen replacement therapy in asthmatic postmenopausal women. Maturitas 1992;21:153-7.

18 Myers JR, Sherman CB. Should supplemental estrogens be used as steroid sparing agents in asthmatic women? Chest

19 Collins LC, Peiris A. Bronchospasm secondary to replacement oestrogen therapy. Chest 1993;104:1300-2

20 Baron JA, La Vecchia C, Levi F. The antiestrogenic effect of Baron JA, La Vecchia C, Levi F. The antiestrogenic effect of
cigarette smoke in women. Am f Obstet Gynecol 1990;162: 502-14.

21 Key TJ, Pike MC, Brown JB, et al. Cigarette smoking and urinary oestrogen excretion in premenopausal and postmenopausal women. Br f Cancer 1996;74:1313-6.

22 Torén K, Brisman J, Järvholm B. Asthma and asthma-like symptoms in adults assessed by questionnaires. Chest 1993; 104:600-8. 